\title{
Strategi Mikro Kepala Sekolah Membudayakan Budaya Malu Sebagai Nilai Karakter Unggul Sekolah Dasar Di Kabupaten Sintang
}

Daniel Dike ${ }^{1}$, Lusila Parida ${ }^{2}$ Ivan Stevanus ${ }^{3}$

${ }^{1,2}$ STKIP Persada Khatulistiwa Sintang

${ }^{3}$ Universitas Katolik Indonesia Atmajaya Jakarta

dikedanieltukan@gmail.com¹, 301086LP@gmail.com² ${ }^{2}$ ivan.pgsd@gmail.com ${ }^{3}$

\begin{tabular}{|c|c|}
\hline INFO AF & RTIKEL \\
\hline Riwayat A & rtikel: \\
\hline Menerima & : 18 Nopember 2 \\
\hline Revisi & : 08 Maret 2021 \\
\hline Diterima & : 08 April 2021 \\
\hline
\end{tabular}

Kata Kunci:

budaya malu, kinerja moral, karakter moral

Keywords:
$\begin{aligned} & \text { shame culture, } \\ & \text { performance, } \\ & \text { character }\end{aligned}$

Korespondensi:

Daniel Dike

STKIP Persada Khatulistiwa

Sintang

Email:

dikedanieltukan@gmail.com

\begin{abstract}
ABSTRAK
Kesadaran moral anak sangat penting dikembangkan dan dibudayakan sejak pendidikan sekolah dasar melalui strategi membudayakan budaya malu. Tujuan penelitian ini adalah mendeskripsikan praktik budaya malu di sekolah dasar SDN 23 Menyumbung kabupaten Sintang. Penelitian ini menggunakan pendekatan studi kasus (one case study research).Teknik pengumpulan data menggunakan wawancara mendalam, observasi dan studi dokumen. Alat pengumpulan data adalah panduan wawancara, lembar observasi dan dukumen. Analisis data menggunakan pola induktif model Creswel. Subyek penelitian adalah guru dan siswa di SDN 23 Menyumbung sebanyak 25 orang. Teknik pengambilan responden secara purposive karena mempertimbangkan situasi pandemi covid 19. Hasil penelitian menunjukan bahwa pade level siswa dan guru dikembangkan 10 budaya malu yang ditanamkan dalam pembelajaran maupun melaui pembiasaan. Praktik budaya malu telah menumbuhkan dua aspek penting dalam diri siswa dan guru yakni karakter kinerja dan kinerja moral. Agar karakter kinerja dan karakter moral tumbuh dengan baik di sekolah maka diperlukan strategi micro kepala sekolah yang terarah pada penguatan identitas personal dan sosial siswa secara moral.
\end{abstract}

\section{ABSTRACT}

Children's moral awareness is very important to be developed and cultivated since elementary school education through a strategy of cultivating a culture of shame. The purpose of this study is to describe the practice of shame culture in elementary schools of SDN 23 Menyumbung, Sintang district. This research uses a case study approach (one case study). Data collection techniques using in-depth interviews, observation and documentation study. Data analysis used the Creswell model inductive pattern. Data collection techniques using in-depth interviews, observation and document study. Data collection tools were interview guides, observation sheets and documents. The research subjects were 25 teachers and students at SDN 23 Menyumbung. The technique of taking respondents was purposive because it considered the covid pandemic situation 19. The results showed that at the level of students and teachers 10 shy cultures were instilled in learning and through habituation. The practice of shame culture has fostered two important aspects in students and teachers, namely the character of performance and moral performance. In order for the performance character and moral character to grow well in school, a micro principal strategy is needed that is aimed at strengthening the personal and social identity of students morally. 
terkait persoalan moralitas bangsa Indonesia. Sering terdengar lantang dan terus dibicarakan diberbagai kalangan dan lapisan masyarakat terkait persoalan pembangunan karakter dan akhlak bangsa. Institusi pendidikan tidak luput dari sorotan persoalan moralitas tersebut. Bahkan institusi pendidikan telah merespon berbagai fenomena dan tindakan korupsi, radikalisme, isu sosial SARA dan terorisme yang semakin marak terjadi akhir-akhir ini.

Pemerintah dan seluruh institusi pendidikan telah melaksanakan kebijakan pendidikan karakter secara nasional dan sudah dilaksanakan melalui kebijakan dan program edukatif di level sekolah dan masyarakat. Namun demikian belum banyak ditemukan hasil konstruktif yang menonjol dari pendidikan karakter nasional dalam mencegah atau memberantas berbagai persoalan moral bangsa karena aktor dan pelaku pendidikan dan kaum intelektual sering terjerat dalam berbagai kasus dan persoalan moralitas seperti tindakan korupsi, radikalisme dan terorisme.

Budaya malu sebagai satu instrumen kunci menghidupkan kembali moralitas bangsa belum banyak dibudayakan dikalangan masyarakat (Fahmi Riady, 2015). Pada institusi pendidikan seperti sekolah-sekolah juga belum terlihat memberi perhatian khusus pembudayaan budaya malu melalui strategi mikro kepemimpinan. Budaya malu juga belum menjadi sebuah program kunci untuk mendukung pelaksanaan program penguatan dan perluasan pendidikan karakter untuk mengembangkan sebuah budaya menciptakan apa yang disebut dengan performance character character moral (Altalib et al., 2019; Kurniawan, 2016).

Budaya malu (ashamed, shame culture) dalam konteks riset ini lebih terarah pada sebuah pemahaman terkait suatu kondisi di mana seseorang merasa bersalah jika melakukan suatu perbuatan yang tidak pantas atau yang bukan seharusnya atau sepantasnya (troubled by guilty feeling), sehingga orang yang melakukan tindakan tersebut merasa terus menerus terganggu, atau dihakimi oleh rasa bersalah dalam dirinya (Damanik Rafandi, 2017). Dengan demikian rasa bersalah dan rasa malu bisa menjadi titik penting bagi perubahan baru perilaku yang lebih konstruktif yang memperlihatkan suatu kualitas moralitas secara individual maupun komunal.

Pertumbuhan kesadaran moral akan nilai-nilai kebaikan pada anak-anak sangat penting dikembangkan serta dibudayakan sejak pendidikan sekolah dasar. Pada level yang paling dasar rasa malu dalam pandangan banyak orang dimulai pada aspek tata krama, sopan-santun dalam berpakaian, bertutur kata maupun bersikap ramah dan hormat terhadap orang lain. Pada level keramah-tamahan dan kesopanan dalam berpakaian, bertutur kata, menyambut tamu masyarakat Indonesia diakui lebih unggul. Pengakuan para turis atau wisatawan asing yang berkunjung ke Indonesia ketika ditanyai kesan tentang Indonesia, selalu dengan gampang mengungkapkan kekaguman mereka soal familiaritas atau keramah-tamahan maupun kesantunan ataupun fraternitas dari warga Indonesia. Namun ketika level rasa malu dikaitkan dengan budaya korupsi atau budaya 
disiplin hidup bersih warga Indonesia harus meneladani atau berguru kepada bangsa lain seperti bangsa Jepang.

Budaya malu yang dimiliki warga Jepang telah mengubah dan membentuk perilaku karakter yang kuat dalam diri warganya. Para pejabat pemerintah dengan sangat cepat menyampaikan permintaan maaf di mimbar publik bahkan mereka langsung mengundurkan diri dari jabatannya ketika gagal, atau melakukan kesalahan kecil sekalipun. Budaya malu menjadi sebuah standar moral warga, standar moral bangsa. Sebagai standar moral budaya malu diajarkan dan dibiasakan sejak masa anak-anak dalam lingkungan keluarga, lingkungan sosial dan institusi-intitusi pendidikan. Bagaimana dengan pendidikan di Indonesia dalam membudayakan budaya malu? Tentu budaya malu belum menjadi bagian dari kultur dan karakter bangsa seperti yang menonjol begitu khas dalam karakter bangsa Jepang.

Implementasi nilai-nilai karakter di sekolah dasar sesungguhnya tidak cukup dengan kebijakan makro mengedepankan enam nilai karakter utama yang dipromugulasikan dalam desain nasional pendidikan karakter. Perluasan dan pengembangan nilai karakter di sekolah harus ditunjang dengan kreativitas inovsi kebijakan manajemen di level mikro kepemimpinan kepala sekolah dalam pengembangan dan perluasan nilai dan sikap karakter unggul di sekolah dasar. Kreativitas manajemen mikro untuk habituasi nilai karakter oleh kepala sekolah perlu diinovasi sesuai kondisi sekolah seperti program operasi semut yang dilakukan oleh kepala sekolah SDN 07 Sintang dalam mendukung program literasi lingkungan atau sekolah Adiwiyata di level keseharian siswa dan guru. Hasil yang terlihat bahwa pengetahuan, kesadaran dan sikap menghargai kebersihan lingkungan sekolah meningkat dan menciptakan atmosfir budaya lingkungan secara positif, lingkungan jadi asri dan menginspirasi warga sekolah dalam aspek literasi sekolah (Dike \& Parida, 2020). Siswa juga memiliki pemahaman yang baik, dan tumbuh rasa malu yang kuat jika membuang sampah di halaman sekolah maupun di ruangruang kelas karena sebelum masuk dan meninggalkan ruangan para guru dan siswa sudah memiliki kepedulian, kesadaran diri dalam menjaga kebersihan lingkungan kelas. Lebih dari itu kesadaran nilai dan perilaku budaya malu membuang sampah sudah ditanamkan dalam kesadaran kolektif warga sekolah meskipun masih terpola atau terbangun dari aspek aturan dan disiplin sekolah sehingga siswa begitu taat dan sadar untuk menjaga kebersihan lingkungan sekolahnya.

Strategi mikro dilevel kebijakan pembelajaran maupun habituasi nilai karakter semakin memperkuat dimensi pengembangan dan perluasan nilai-nilai karakter di sekolah dasar. Hal ini penting untuk mengubah perspektif bahwa pendidikan karakter di sekolah masih sebatas penanaman normanorma dan aturan sekolah. Beberapa riset pendidikan karakter di sekolah menyimpulkan bahwa pendidikan karakter masih sebatas penegakan norma-dan aturan sekolah dan belum masuk dalam ranah pembiasaan nilai- 
nilai kehidupan (Akuntoro, 2011; Endang Poerwanti, 2013; \& Parida., Sirhi \& Dike, 2019; Said Samsudin, 2018). Meskipun demikian bebeperapa sekolah secara terbatas sudah menunjukan level pembiasaan nilai karakter sebagai pola dan sistem nilai hidup. Program operasi semut di SDN 07 juga kegiatan Jumat bersih di sekolah-sekolah sedikit banyak terbukti membantu penanaman nilai karakter dan budaya malu siswa untuk tidak membuang sampah sembarangan di sekolah. Kegiatan ini juga memperkuat kesadaran nilai serta sikap tanggung jawab guru dan siswa dalam menjaga dan merawat lingkungan sekolah.

Budaya malu menjadi karakter kunci yang perlu dibangun dalam pembelajaran maupun pembiasaan nilai karakter di sekolah dasar yang seharusnya didukung atau berkorelasi dengan sistem sosial di masyarakat. Ekspresi budaya malu di SDN 23 Menyumbung ditunjukan melalui kebijakan budaya malu untuk membuang sampah sembarangan, malu berpakaian kotor, malu untuk berkelahi, malu jika nilai jelek, malu jika datang terlambat. Contoh kebijakan dan pembiasaan seperti ini tidak sekedar memenuhi aturan dan norma sekolah tetapi sebagai sebuah strategi sekolah dalam penanaman kesadaran nilai dan kecakapan sosial siswa.

Praktik kebijakan micro di level sekolah dasar terkait budaya malu di SDN 23 Menyumbung Sintang, mendorong peneliti menggali lebih jauh untuk menemukan orientasi, tujuan, dampak dan hasil dari pembudayaan budaya malu di level pendidikan sekolah dasar. Tujuan dari penelitian ini adalah mendeskripikan praktik pembudayaan budaya malu dan pendekatan strategi micro kepala sekolah dalam program penguatan dan perluasan pendidikan karakter. Penelitian kualitatif ini membantu memberi perspektif dan makna baru yang lebih nyata terkait manajemen strategi micro dari sisi kebijakan pendidikan dan pembudayaan karakter. Tentu melalui program pembudayaan budaya malu di sekolah dasar dapat terlihat capaian perluasan dan pendalaman program pendidikan karakter di level sekolah dasar.

\section{METODE PENELITIAN}

Penelitian ini menggunakan case study research dengan pertimbangan bahwa sebuah kasus merupakan sarana penelitian emik dalam menggali pemikiran, konsep, makna dan strategi mikro yang diterapkan di sekolah yaitu hal-hal aktual dalam interaksi potensial subyek-subyek pendidikan yaitu siswa dan guru di sekolah (Densin, \& Lincoln, 2013; Olive, 2014;Yin, 2009). Studi ini mengungkap kebijakan pengalaman kepala sekolah, guru, siswa terkait pengalaman belajar yang berlangsung secara unik di sekolah termasuk konteks masa pandemi covid 19 di kota Sintang. Pilihan metode ini sesuai karakteristik studi kasus karena subyek yang diteliti memiliki keunikan situasional maupun paparan data yang dapat disajikan secara menyeluruh sesuai pengalaman aktual praktik pendidikan seperti pembudayaan budaya malu di sekolah perkotaan dan pedalaman Kalimantan Barat (Ary, D., Jacobs, L.C., \& Sorensen, 2010; Cohen, L., Manion L., \& 
Morrison, 2018; Densin, K.D., \& Lincoln, 2013).

\section{Tempat, Waktu dan Subyek Penelitian}

Penelitian ini dilakukan di sekolah SDN 23 Menyumbung, dalam kurun waktu Juli sampai Oktober tahun 2020. Penentuan lokasi penelitian dan subyek sekolah menggunakan teknik purposive sampling area. Pemilihan lokasi penelitian ini diambil dengan pertimbangan khusus sesuai tujuan khusus dari kegiatan penelitian (Densin, K.D., \& Lincoln, 2013). Subyek penelitian ditentukan melalui metode purposive sampling artinya subyek ditetapkan berdasarkan pertimbangan dan tujuan khusus yang dicapai (Leavy, 2017). Informan yang dipilih adalah 1 orang kepala sekolah, 8 orang guru, 6 orang siswa yang mewakili kelas tinggi dan kelas rendah. Kepala sekolah dipilih sebagai subyek karena dialah pemimpin yang memiliki kewenangan terhadap kebijakan micro membudayakan budaya malu di sekolah. Guru dipilih karena pertimbangan peran sentralnya dalam praktik pembudayaan dan pengajaran nilai-nilai budaya malu di sekolah dan ruang-ruang kelas sesuai jenjang kelas di Sekolah Dasar. Siswa merupakan subyek bina yang menjalankan budaya malu yang dicanangkan di sekolah sebagai program khas dan atau program unggulan sekolah untuk membuminkan pendidikan karakter agar lebih tepat sasaran untuk guru dan siswa di SDN 23 Menyumbung.

\section{Data, Intrumen, dan Teknik Pengumpulan Data}

Perolehan data dilakukan melalui wawancara mendalam terhadap kepala sekolah, guru, siswa terkait praktik budaya malu di sekolah dasar. Studi kasus ini mengintegrasikan data observasi, wawancara, dan studi dokumen untuk mengelaborasi praktik budaya malu di sekolah (Leavy, 2017). Pusat amatan adalah kegiatan kepala sekolah, guru dan siswa, dalam proses pembudayaan 10 budaya malu baik pada level siswa maupun guru. Temuan observasi (auto observation) dikomparasikan dengan hasil wawancara, dan studi dokumen. Proses triangulasi ini berfungsi untuk memvalidasi data sehingga mencapai wawasan mendalam tentang pengalaman dan makna hakiki dari data terkait praktik pembudayaan budaya malu di sekolah (Densin, K.D., \& Lincoln, 2013).

\section{Teknik Analisis Data}

Proses analisis data ditempuh melalui hasil wawancara, observasi dan studi dokumen, dirangkum dan dikaji secara teliti sehingga menghasilkan data yang valid. Responden kepala sekolah, guru dan siswa dimintakan konfirmasinya kembali terhadap simpulan hasil wawancara, observasi dan studi dokumen yang sudah dirangkum untuk memastikan akurasi, kredibilitas dan validitas data. Analisis data dilakukan secara induktif dengan pola interaktif(Ary et al., 2006). Data yang diperoleh dari hasil wawancara dan amatan memiliki kontribusi langsung maupun tidak langsung dari berbagai sumber dan perspektif sehingga meningkatkan akurasi dan keandalan data (Leavy, 2017; Maxwell \& Reybold, 2015). Unit analisis adalah kepala 
sekolah, guru dan siswa karena ketiganya menjadi bagian penting dan saling terkait satu sama lain dalam proses pembudayaan budaya malu di sekolah. Akhirnya seluruh sajian data dan analisis data bermuara pada satu kesimpulan yang diambil secara induktif (Baxter \& Jack, 2008; Ritchie, 2003).

\section{HASIL DAN PEMBAHASAN}

Dari hasil observasi, wawancara dan studi dokumentasi yang dilakukan ditemukan bahwa ada dua hal menarik dalam program pendidikan karakter di SDN 23 Menyumbung yang berbeda dengan sekolah lain yang ada di kota Sintang. Secara eksplisit kepala sekolah memiliki strategi micro terkait dengan implementasi penguatan dan perluasan pendidikan karakter di sekolah dasar. Sekolah memprogramkan dan membudayakan budaya malu sebagai salah satu keunggulan program dan keunggulan nilai karakter siswa dan guru yang dibangun dengan sebuah sistem nilai dan perilaku karakter.

Pada level siswa ada 10 budaya malu yang ditanamkan sebagai bagian yang penting di luar pembelajaran formal di ruang kelas. Dapat dikatakan 10 nilai budaya malu tersebut merupakan aspek hidden curriculum yang dikembangkan sekolah dalam membangun dan membentuk karakter unggul siswa. Sepuluh budaya malu tersebut adalah (1) saya malu kelas kotor (2) saya malu tidak mengerjakan PR, (3) saya malu mencontek (4) saya malu membuang sampah sembarangan (5) Saya malu berkelahi (6) saya malu melawan guru (7) saya malu berkata kasar (8) saya malu nilai jelek (9) saya malu datang terlambat (10) saya malu berpakaian kotor. Sepuluh point budaya malu ini merupakan bagian penting dari implementasi visi SDN 23 Menyumbung yakni "Terwujudnya Peserta Didik yang Beraklaq Mulia, Berprestasi, Berkarakter, Berwawasan Lingkungan dan Disiplin."

Strategi micro membudayakan budaya malu yang digagas oleh sekolah dikembakan melalui kepemimpinan partisipatif guru. Partisipasi ini memberi ruang fleksibel dan adaptif dalam pengembangan perilaku dan pengembangan nilai-nilai karakter siswa dalam pembelajaran. Pembudayaan budaya malu dilevel siswa dilakukan secara serentak dan terintegrasi sehingga baik siswa maupun guru menjalankan nilai-nilai tersebut sebagai bagian dari kesadaran komunitas akan identitas keunggulan sekolah dengan tekad untuk siap berkarya dan mengharumkan nama sekolah.

Pada level guru juga ada 10 aspek budaya malu yang menjadi nilai karakter yang dihidupi dalam praktik keseharian dan pengembangan kinerja dan profesionalisme dalam skema pendalaman dan perluasan pendidikan karakter di sekolah. 10 point budaya malu pada level guru ini merupakan sebuah aspek yang seimbang atau setara dengan 10 nilai budaya malu dilevel siswa. Kesepuluh budaya malu pada level guru yakni (1) aku malu datang terlambat (2) aku malu pulang awal (3) aku malu tidak masuk kerja (4) aku malu terlalu sering minta izin (5) aku malu berpakaian tidak sesuai aturan (6) aku malu tidak mempunyai program (7) aku malu pekerjaan terbengkelai (8) aku malu bekerja 
tanpa pertangungjawaban (9) aku malu bila tempat kerja kotor (10) aku malu tidak bertata krama dan sopan santun.

Sepuluh aspek budaya malu yang diterapkan di level guru merupakan salah satu satu strategi micro kepala sekolah dalam mengembangkan pendidikan karakter dengan menempatkan guru sebagai suri teladan. Keteladan guru adalah kunci penting keberhasilan habituasi dan pengajaran nilainilai karakter sehingga para pendidik perlu menunjukan karakter unggul sesuai apa yang diwajibkan secara moral dan etis dalam kode etik guru Indonesia. Sebagai bagian penting dari pembudayaan dan pembiasaan nilai budaya malu 10 point karakter tersebut merupakan wujud nyata untuk membumikan motto atau semangat pelayanan dan pengabdian guru di SDN 23 Menyumbung yakni "Kami berkaya untuk maju dan kami siap mengharumkan nama SDN 23 Menyumbung Sintang." Spirit ini secara ekplisit sudah tergambar dari tampilan fisik sekolah yang dihiasi dengan berbagai gambar dan tulisan di dinding sekolah. Gambaran ini merepresentasikan nilai-nilai, semangat dan karakter unggul yang dikembangkan secara spesisifk di sekolah sebagai sebuah strategi manajemen micro di level sekolah.

Saat memasuki gerbang sekolah sudah terlihat di dinding spanduk yang bertuliskan visi misi sekolah yang dilengkapi dengan gambar foto kepala sekolah, jajaran guru dan staf. Pada dinding-dinding luar dan dalam kelas juga sudah dipampang visi misi dengan gambar formasi lengkap seluruh guru, gambar siswa, karya siswa, penantaan taman bunga yang indah. Keadaan aktual dan fisik sekolah adalah simbol yang mengekspresikan semangat kekompakan dan cita-cita besar memajukan SDN 23 Menyumbung sesuai visi dan misi yang telah disepakati dan ditetapkan bersama sebagai satu tim guru yang kompak, energik dan berkarakter. Hal ini dapat terlihat dari beberapa dokumen gambar yang dibingkai dan digantung di dinding depan sekolah, di dinding samping ruang kepala sekolah, ruang guru dan ruang-ruang kelas. Gambar-gambar ini merupakan wujud dan upaya strategi micro kepala sekolah paa level hidden curriculum untuk membudayakan budaya berkemajuan yang didukung dengan standar nilai dan perilaku hidup, sikap dan profesionalisme. Semua aspek yang didukung dengan penciptaan lingkungan yang hijau dan asri adalah cerminan dari penciptaan karakter unggul sekolah. Meskipun sekolah ini memiliki konstruksi sekolah panggung, karena tiap tahun selalu mengalami bencana banjir tak mengurangi semangat dan usaha untuk menanam bunga dan tanaman hias maupun apotik hidup. Beberapa contoh gambar dan tulisan di bawah ini bisa mewakili strategi micro kepala sekolah dalam proses literasi lingkungan dan pembudayaan budaya malu baik di level guru maupun siswa dalam rangka memperkuat karakater unggul siswa dan guru. 


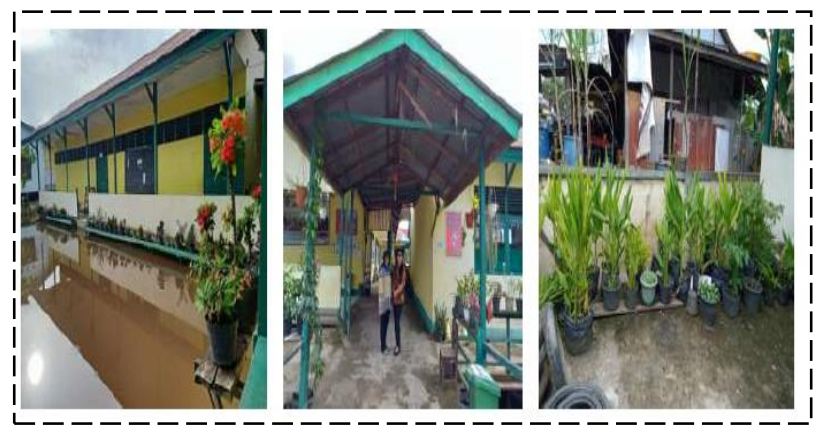

Gambar.1 Gambar situasi lingkungan sekolah dan proses literasi lingkungan sebagai bagian dari implementasi budaya malu (malu kalau tidak punya program kerja).

Pembudayaan budaya malu dalam praktiknya sangat terintegrasi dengan pembelajaran nilai karakter di level mata pelajaran dan kegiatan kelas. Dalam wawancara dengan wali kelas II, III, dan V SDN 23 diungkapkan bahwa aspek-aspek budaya malu diintegrasikan dengan tema-tema dan topik-topik tematik yang relevan dan cocok dengan 10 budaya malu yang digagas dan dikembangkan sekolah. Bahkan lebih jauh nilai-nilai selalu dikaitkan dengan aspek religius dan ajaran keagamaan karena mayotitas siswa beragama Islam dan komunitas masyarakat di sekitar sekolah adalah masyarakat Melayu Muslim. Jadi identitas budaya malu juga merupakan bagian dari implementasi nilai-nilai religius yang ditanamkan melalui proses pendidikan sejak usia dini dalam satu komunitas pendidikan yang terbuka terhadap keberagaman. Karena itu anak-anak ditanamkan dalam dirinya rasa malu yang besar terhadap perbuatan atau tindakan yang kurang pantas atau yang bertentang dengan nilai-nilai moral dan nilainilai keagamaan.

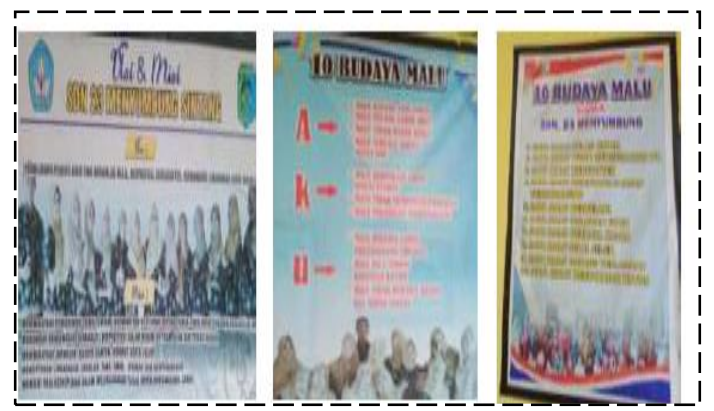

Gambar 2. Visi Misi dan Budaya Malu yang di pajang di dinding sekolah SDN 23 Menyumbung, Sintang

Dalam praktik pembelajaran dan keseharian siswa di luar jam belajar misalnya budaya "saya malu kalau kelas kotor, saya malu tidak mengerjakan $P R$, saya malu mencontek atau saya malu membuang sampah sembarangan" diajarkan dan dibentuk dalam proses pembelajaran dan latihan praktis seperti pembagian jadwal piket menyapu kelas, menyapu halaman sekolah, menyiram bunga maupun tanaman apotik hidup lokal. ditumbuhkan sejak usia dini.

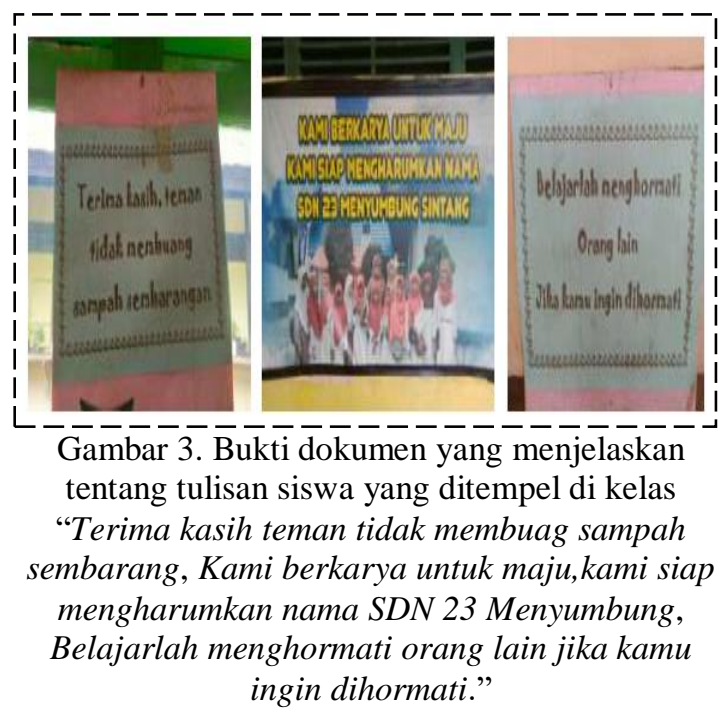

Kesadaran kognitif akan nilai dan perilaku budaya malu juga didesain dalam pembelaajaran karakter dan kegiatan literasi kelas yang terinclude dengan pembelajaran 
seperti membuat qout atau kata-kata bijak yang ditulis dan ditempelkan di dalam ruang kelas. Tindakan dan proses ini sebagai upaya membangun ingatan dan kesadaran kolektif siswa terkait budaya malu yang harus ditanamkan dalam kesadaran kognitif dan kesadaran sosial kolektif warga sekolah.

Beberapa tulisan di ruang kelas dan aktivitas di lingkungan sekolah sangat eksplisit menjelaskan pembudayaan budaya malu yang dibudayakan di SDN 23 Menyumbung Sintang. Proses ini menjadi bagian penting dari penguatan dan perluasan nilai-nilai karakter baik di level individu siswa, level kelas dan sekolah sebagai satu komunitas terdidik.

Pemaparan hasil yang tergambar pada uraian dan didukung oleh dokumen yang aktual sebenarnya menggambarkan secara gamblang dan terang strategi micro pendidikan karakter yang dikembangkan oleh kepala sekolah di SDN 23 Menyumbung. Hal ini menunjukan dua apsek penting dari pendidikan karakter dilevel guru dan siswa yakni aspek "performance character dan moral character sebagai jalan sukses sekolah di dalam proses dan kinerja belajar siswa dan kinerja kerja guru. Performance character lebih mengacu pada disposisi kognitif, emosional, dan perilaku yang diperlukan siswa maupun guru untuk mencapai keunggulannya sebagai manusia dalam lingkungan kinerjanya kegiatan ekstrakurikuler, maupun tugas dan pekerjaan lain yang diberikan kepada siswa dan guru di sekolah. Sedangkan karakter moral lebih mengacu pada disposisi bathin yang diperlukan untuk fungsi etis yang mencakup kualitas seperti kesadaran dan penghayatan terhadap nilai-nilai maupun prinsip-prinsip keadilan, kepedulian, rasa hormat, dan kejujuran (Davidson, 2020).

Dalam rangka memperkuat dan mengembangkan budaya malu sebagai bagian penting dari pengembangan kinerja moral siswa dan guru maka strategi micro yang perlu dihidupkan oleh kepala sekolah sebagai pemangku kebijakan adalah mengupayakan beberapa hal berikut seperti membantu siswa menjadikan karakter sebagai inti dari identitas mereka. Siswa ditantang untuk mendefinisikan siapa mereka dengan cara yang melampaui harta dan prestasi yang ingin mereka raih. Guru juga dalam pembelajaran dapat meminta siswa agar secara teratur bergulat dengan pertanyaan eksistensial seperti apa arti hidup? apa itu kebahagiaan? apa yang membuat siswa memiliki tujuan yang positif dalam proses belajar mereka (Davidson Matt, 2020). Beberapa pertanyaan menantang ini akan membawa siswa pada proses refleksi diri untuk mengembangkan kesadaran tentang nilai-nilai budaya malu yang mereka hidupi sehingga sepuluh aspek budaya malu yang dikembangkan sekolah tidak hanya berhenti pada formalisme pelaksanaan aturan dan norma sekolah tetapi menjadi bagian inti dari proses habituasi nilai-nilai kehidupan, dan pada saat yang sama para siswa mampu mengembangkan perfomance moral mereka baik secara individual maupun secara kolektif. Hal ini sebenarnya telah dipraktikan dalam pendidikan sekolah dasar di Jepang melalui pembelajaran "time for moral yang memungkinkan siswa membangun refleksi diri 
tentang nilai-nilai dasar moral yan dibangun pada suatu konsep habituasi nilai-nilai moral dan karakter pada jam-jam moral (time of moral) yang diprogramkan di sekolah (Gusarova, 2015; Parida., Sirhi \& Dike, 2019).

Pada level guru diperlukan adanya inovasi dalam penguatan dan perluasan pendidikan karakter dengan menyiapkan fasilitas atau alat pemantauan diri untuk mengukur kemajuan siswa pada aspek budaya malu menuju tujuan hakiki atau tujuan fundamental dari proses pendidikan anak. Siswa dapat mencatat upaya mereka untuk meningkatkan keterampilan pada bidang tertentu sementara tugas guru adalah membantu siswa menganalisis kemajuan yang dicapai dan merevisi rencana tindakan sesuai kebutuhan belajar siswa secara individual atau kolektif (Davidson, 2020). Melalui upaya strategi micro kebijakan dan praktik budaya malu semacam ini membuat siswa mampu mempertahankan integritas akademiknya dan memperkuat pemahaman dan sikap siswa terkait bagaimana semua bentuk kecurangan dan plagiarisme (kegiatan menyontek) yang sering terjadi di sekokolah dapat dihilangkan atau perlahan-lahan menurun dalam dunia pendidikan karena siswa sadar perilaku semacam ini merugikan dirinya sendiri dan orang lain. Pembudayaan budaya malu semacam ini merupakan sebuah pola penyadaran dan pembiasaan nilai moral dan karakter yang dibentuk secara alimiah dan natural di dalam proses pendidikan.

Peran kepemimpinan kepala sekolah dalam menciptakan budaya sekolah di mana integritas akademik adalah sebuah norma moral dan kinerja moral yang patut dihidupi dan dikembagkan di sekolah sebagai mentalitas yang mengedepankan integritas diri sebagai kaum intelektual yang sejak dini di sekolah dasar (Dike,. Parida., Sirhi., 2019; \& Parida., Sirhi \& Dike, 2019). Habituasi nilai moral dan karakter ini membutuhkan peran strategi micro kepala sekolah melibatkan peran serta orangtua dalam penanaman nilai karakter dan moral sejak dini (Adpriyadi1 \& Sudarto, 2020). Dengan demikian kepala sekolah dan para guru memperlihatkan sikap dan profesionalitas mereka sebagai pendidik untuk membantu siswa melihat perbedaan antara kinerja (hasil) dan karakter kinerja sebagai upaya gigih melakukan yang terbaik dari diri setiap anak (Carr, 2017; Gaskarth, 2012; Wright, 1978).

Dari uraian di atas terlihat jelas bahwa pembudayaan budaya malu pada level siswa dan level guru seperti budaya "aku malu datang terlambat, aku malu pulang awal, aku malu tidak masuk kerja, aku terlalu sering minta izin, aku malu berpakaian tidak sesuai aturan, aku malu tidak mempunyai program, aku malu pekerjaan terbengkelai, aku malu bekerja tanpa pertangung jawaban, aku malu bila tempat kerjanya kotor dan aku malu tidak bertata krama sopan santun" memperlihatkan dua sisi sekaligus sebagai hasil dari kinerja belajar mengajar yang guru lakukan sebagai tugas rutin pengajaran dan sekaligus menunjukan kinerja moral pendidikan (moral performance) yang terkait dengan upaya gigih sekolah dalam menciptakan program dan caracara edukatif yang mumpuni dalam memperluas dan menguatkan nilai dan 
perilaku karakter unggul siswa dan guru di sekolah dalam membentuk perilaku pelajar Pancasila dengan kualitas-kualitas nilai-nilai moral yang sesuai dengan karakter bangsa seperti memiliki berakhlak mulia, mandiri, bernalar kritis, kreatif, bergotong royong dan berkebhinekaan global (Kemdikbud, 2020; Kemendikbud, 2010). Strategi micro kepemimpinan kepala sekolah dalam membudayakan budaya malu juga dapat mengakomodir nilai-nilai kearifan lokal karena nilai-nilai kearifan lokal adalah fondasi bagi terbentuknya karakter bangsa. Pada konteks pendidikan sekolah dasar dan pendidikan usia dini akomodasi kearifan lokal seperti budaya Dayak Desa dan budaya Melayu akan membantu proses terbangunnya atmosir pengembangan nilai-nilai moral dan karakter siswa sebagai bagian dari pewarisan nilai-nilai luhur budaya lokal yang dihidupkan melalui institusi pendidikan (Fransiska \& Suparno, 2019; Rohani, Fety Novianty;, 2018).

\section{SIMPULAN}

Dari uraian hasil dan pembahasan yang telah dipaparkan dapat diambil beberapa kesimpulan sebagai berikut:

1. Strategi micro yang dikembangkan sekolah dalam pembudayaan dan perluasan nilainilai pendidikan karakter terwujud lewat kebijakan sekolah mengembangkan 10 apsek budaya malu baik di level siswa mapun guru sebagai acuan kenerja karakter dan karakter moral di sekolah dasar SDN 23 Menyumbung, Sintang.
2. Pembudayaan budaya malu di level sekolah telah menghidupakan dan mengembangkan kultur, iklim dan atmosfir kekayaan nilainilai moral yang diperkuat dengan nilainilai religius dan kebijaksaan budaya lokal Melayu tetapi tetap terbuka terhadap keberagaman dan toleransi yang kuat.

3. Pembudayaan budaya malu di sekolah bagi siswa dan guru mampu mengembangkan kinerja moral dan karakter moral siswa dan guru sebagai bagian dari upaya membangun identitas sekolah dan karakter unggur siswa dan guru.

Agar aspek budaya malu dapat menjadi strategi micro yang kuat di level kelas dan sekolah maka siswa maupun guru perlu terus mengembangkan budaya mutu untuk membantu siswa menjadikan karakter sebagai inti dari identitas personal dan sosial mereka. Guru juga perlu menantang siswa dalam setiap pembelajaran di kelas atau luar kelas untuk mendefinisikan identitas diri dan sosial mereka yang melampaui harta dan prestasi yang ingin mereka raih (Dike et al., 2020).

Dalam pembelajaran karakter guru dapat meminta siswa untuk secara teratur bergulat dengan pertanyaan eksistensial terkait arti hidup, arti belajar, arti kebahagiaan dan untuk menemukan apa yang membuat belajar mereka memiliki tujuan yang positif (Budiarta \& Krismayani, 2014; Gaskarth, 2012). Untuk itu sangat diperlukan manajemen kepala sekolah yang integratif dalam mengakomodir baik pengembangan kinerja moral maupun karakter moral siswa dan guru melalui manajement hexagonal yang menghidupkan komponen 
mutu pendidikan secara utuh dan terintegrasi

(Dike \& Parida, 2019; Ozkan, 2015).

\section{DAFTAR RUJUKAN}

Adpriyadi \& Sudarto. (2020). Pola asuh demokratis orangtua dalam pengembangan potensi diri dan karakter anak usia dini. VOX EDUKASI: Jurnal Ilmiah Ilmu Pendidikan, 11(April), 2638.

https://jurnal.stkippersada.ac.id/jurnal/ind ex.php/VOX/article/view/572/pdf

Akuntoro, I. (2011, December). Gagalnya Pendidikan Karakter Kesalahan Pendidikan? Kompas.Com. https://doi.org/http://edukasi.kompas.com $/ \mathrm{read} / 2011 / 12 / 12 / 10273315 /$ gagalnya.pen didikan.karakter.kesalahan.pendidikan

Altalib, H., AbuSulayman, A., \& Altalib, O. (2019). Character Building Cannot Wait. In Parent-Child Relations (pp. 135-158). International Institute of Islamic Thought.

https://doi.org/10.2307/j.ctvktrvqn.13

Ary, D., Jacobs, L.C., \& Sorensen, C. (2010). Introduction to research in education (eighth). wadsworth Cengage Learning.

Ary, D., Jacobs, L. C., Sorensen, C., \& Razavieh, A. (2006). Introduction to research in education (eight). wadsworth Cengage Learning.

Baxter, P., \& Jack, S. (2008). Qualitative case study methodology: Study design and implementation for novice researchers. The Qualitative Report, 13(4), 544-559. https://doi.org/citeulike-articleid:6670384

Budiarta \& Krismayani. (2014). Improving speaking skills and developing character of the students through collaboration of think-pair-share and the concept of tri kaya parisudha.

Carr, D. (2017). Virtue Ethics and Education. In N. E. Snow (Ed.), The Oxford Handbook of Virtue. Oxford University Press. https://doi.org/10.1093/oxfordhb/978019
9385195.013.10

Cohen, L., Manion L., \& Morrison, K. (2018). Research method in education. In Companion Website (Eight). Routledge: taylor \& Francis Group. https://b-ok.asia/

Damanik Rafandi. (2017). Membayakan rasa malu. Kompasiana.Com. https://www.kompasiana.com/1223/592c 9c01537b612839d0f6fb/membudayakanrasa-malu?page $=$ all

Darlington, Y., \& Scott, D. (2002). Qualitative research in practice. Stories from the Field. In Journal of Orthopaedic Nursing (Vol. 6, Issue 4, pp. 237-238). https://doi.org/10.1016/S13613111(02)00100-0

Davidson Matt. (2020). Developing performance character and moral character in youth. Center for the 4th and 5th Rs, School of Education. https://ncyi.org/2017/09/14/developingperformance-character-and-moralcharacter-in-youth/

Densin, K.D., \& Lincoln, Y. . (2013). The sage handbook of qualitative research. In \& Y. S. L. Norman K, Densin . (Ed.), Journal of Chemical Information and Modeling (Fifth, Vol. 53, Issue 9). Sage Plubications. https://b-ok.asia/

Dike, D., \& Parida, L. (2019). Hexagonal management kelas dalam pembelajaran di sekolah dasar. Jurnal Akuntabilitas Manajemen Pendidikan, 7(1), 35-49. https://doi.org/10.21831/amp.v7i1.23268

Dike, D., Parida, L., \& Stevanus, I. (2020). Micro strategy and character educational transformation in elementary school during the covid-19 pandemic of sintang distric, west kalimantan province. European Journal of Molecular and Clinical Medicine, 7(8), 775-786. https://ejmcm.com/article_3196.html

Dike Daniel \& Parida Lusila. (2020). The micro leadership strategy of the principal to implementing character education in elementary school. Prima Edukasia, 8(1), $50-62$. 
https://journal.uny.ac.id/index.php/jpe/art icle/view/29920

Endang Poerwanti. (2013). Sistem indikator nilai-nilai moral universal sebagai evaluasi reflektif pendidikan karakter di TK. Prima Edukasia, I(3), 10-16. https://doi.org/https://doi.org/10.21831/jp e.v1i1.2314

Fahmi Riady. (2015). Membudayakan rasa malu. Kompasiana.Com. https://www.kompasiana.com/himung/55 12babfa333115662ba7d2a/membudayak an-rasa-malu

Fransiska, \& Suparno. (2019). Metode penanaman nilai budaya dalam pengasuhan anak usia dini pada keluarga dayak desa. VOX EDUKASI: Jurnal Ilmiah Ilmu Pendidikan, 10(2), 111-119. https://jurnal.stkippersada.ac.id/jurnal/ind ex.php/VOX/article/view/516/pdf

Gaskarth, J. (2012). The virtues in international society. European Journal of International Relations, 18(3), 431453.

https://doi.org/10.1177/13540661103898 33

Gusarova, A. (2015). Performance and morality as main goals of elementary schools in japan. Procedia - Social and Behavioral Sciences, 182, 692-694. https://doi.org/10.1016/j.sbspro.2015.04. 814

Jansen, H. (2010). The logic of qualitative survey research and its position in the field of social research methods. Forum Qualitative Sozialforschung/ Forum: Qualitative Social Research, 11(2). https://doi.org/10.17169/FQS-11.2.1450

Kemdikbud. (2020). Guru penggerak indonesia maju. Kementrian Pendidikan Dan Kebudayaan. https://sekolah.penggerak.kemdikbud.go. id/gurupenggerak/

Kemendikbud. (2010). Desain Induk Pendidikan Karakter. Kemendikbud. https://muhsinpamungkas.files.wordpress .com/2011/05/desain-induk-pendidikan- karakter-kemdiknas.pdf

Kurniawan, R. (2016). Sitem pendidikan islam terpadu dalam menyingkapi generasi rabbani dan generasi terdidik: Studi pada sistem pendidikan islam terpadu di bawah jaringan sekolah islam terpadu. International Conference on Islamic Epistemology, 92-98.

Leavy, P. (2017). Research design. In The Guilford Press. The Guilford Press. https://b-ok.asia/

Maxwell, J. A., \& Reybold, L. E. (2015). Qualitative Research. In International Encyclopedia of the Social \& Behavioral Sciences: Second Edition (pp. 685-689). Elsevier Inc. https://doi.org/10.1016/B978-0-08097086-8.10558-6

Olive, J. L. (2014). Reflecting on the tensions between emic and etic perspectives in life history research: Lessons learned. Forum Qualitative Sozialforschung, 15(2). https://doi.org/10.17169/fqs15.2.2072

Ozkan, S. (2015). Evaluating learning management systems: Hexagonal elearning assessment (HELAM). European and Mediterranean Conference on Information Systems, European a(January 2008), 1-17. https://www.researchgate.net/publication /237325850_Evaluating_learning_manag ement_systems_Hexagonal_elearning_assessment_model_HELAM

Parida., Sirhi., \& D. (2019). Pola Kepemimpinan Kepala Sekolah Dalam Penguatan Karakter Di Sekolah Dasar Kota Sintang Kalimantan Barat. Profesi Pendidikan Dasar, 1(2), 145-164. https://doi.org/10.23917/ppd.v1i2.9159

Parida., Sirhi, \&, \& Dike. (2019). Habituasi karakter unggul siswa sekolah dasar melalui optimalisasi peran kepemimpinan kepala sekolah di kabupaten sintang. Seminar Nasional Pengelaran Pendidikan Dasar Nasional (PPDN, 200-2014. http://seminar.uad.ac.id/index.php/ppdn/a 
rticle/view/1431

Ritchie, J. Lewis, J. (2003). The Foundations of Qualitative Research. Qualitative Research Practice: A Guide for Social Science Students and Researchers, 2-10. https://doi.org/10.4135/9781452230108

Rohani, Fety Novianty;, \& S. F. (2018). Analisis upaya melestarikan nilai-nilai budaya pada masyarakat adat melayu di kecamatan sungai kakap kabupaten kubu raya. VOX EDUKASI: Jurnal Ilmiah Ilmu Pendidikan, 9(1), 152-162. https://jurnal.stkippersada.ac.id/jurnal/ind ex.php/VOX/article/view/516/pdf

Said Samsudin. (2018, October). Pentingnya pendidikan karakter di sekolah. Kompasiana.Com, 1-3.

Somekh, B., \& Lewin, C. (2005). Research methods in the social sciences. Social Sciences, $\quad 36, \quad 368$. https://doi.org/10.1111/j.14678535.2005.00515_7.x

Wright, I. (1978). Moral reasoning and conduct of selected elementary school students. Journal of Moral Education, 7(3), 199-205. https://doi.org/10.1080/03057247800703 06

Yin, R. K. (2009). Case study research: Design and methods (5th ed.). Sage Publications, Inc. 